Article

\title{
Stability of Two-Dimensional Polymorphs for 10,12-Pentacosadyn-1-ol on Graphite Investigated by SPM
}

\author{
Daisuke Takajo $^{1, *}$ and Koichi Sudoh ${ }^{2}$ \\ 1 Research Center for Structural Thermodynamics, Graduate School of Science, Osaka University, \\ Toyonaka 560-0043, Japan \\ 2 The Institute of Scientific and Industrial Research, Osaka University, Ibaraki 567-0047, Japan; \\ sudoh@sanken.osaka-u.ac.jp \\ * Correspondence: takajo@chem.sci.osaka-u.ac.jp; Tel.: +81-6-6850-5524
}

Received: 16 February 2018; Accepted: 23 March 2018; Published: 27 March 2018

\begin{abstract}
For monomolecular layers of 10,12-pentacosadiyn-1-ol on graphite, it is known that two different two-dimensional polymorphic forms-herringbone $(\mathrm{H})$ and parallel $(\mathrm{P})$ arrangements-are observable at room temperature. Here, we study the thermodynamic stability of these polymorphs by scanning tunneling microscopy (STM) and atomic force microscopy. When the monomolecular films, where $\mathrm{H}$ and $\mathrm{P}$ domains coexist, are annealed at above $40^{\circ} \mathrm{C}$, the area of $\mathrm{P}$ arrangement irreversibly increases, demonstrating that $\mathrm{P}$ arrangement is thermodynamically stable while $\mathrm{H}$ arrangement is quasi-stable. Consistently, invasion of $\mathrm{P}$ domains into $\mathrm{H}$ domains is observed during morphological changes induced by STM scanning at room temperature. Furthermore, we estimate that the melting point of the monomolecular film of $\mathrm{P}$ arrangement is about $80^{\circ} \mathrm{C}$, which is $20^{\circ} \mathrm{C}$ higher than that of the bulk crystal.
\end{abstract}

Keywords: adsorption; polymorphs; stabilization; STM; AFM

\section{Introduction}

In the current field of material chemistry, the on-surface synthesis has attracted great interest as a promising way of creating functional materials [1-5]. Formation of conductive polymer nanowires by chain polymerization in self-assembled monomolecular layers of diacetylene (DA) compounds is expected to be applicable for wiring functional molecules in single-molecule electronics [6-8]. To achieve precise control of the chain polymerization, an understanding of the thermodynamic stability of self-assembled monomolecular layers is crucial.

Previously, we have shown that for monomolecular films of a DA compound, 10,12-pentacosadiyn-1-ol (PCDYol, Figure 1), formed on highly oriented pyrolytic graphite (HOPG) surfaces, two different polymorphic forms-namely herringbone $(\mathrm{H})$ and parallel $(\mathrm{P})$ arrangements-are observed at room temperature [9]. For these polymorphic forms, the reaction efficiencies of the chain polymerization are remarkably different [10]. In this work, we investigate the thermodynamic stability of the two polymorphs of PCDYol monomolecular films, using scanning tunneling microscopy (STM) and atomic force microscopy (AFM). Observing polymorphic transformations by thermal annealing and by stimulation of STM scanning, we find that P arrangement is stable while $\mathrm{H}$ arrangement is metastable. We also show that melting of $\mathrm{P}$ arrangement monomolecular film occurs above $80^{\circ} \mathrm{C}$. 


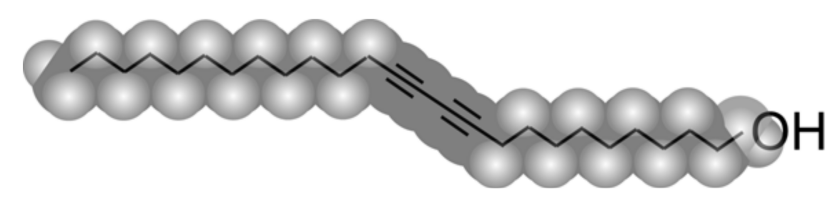

Figure 1. Molecular structure of PCDYol.

\section{Materials and Methods}

\subsection{Sample Preparations}

PCDYol (Tokyo Chemical Industry Co, Ltd., Tokyo, Japan) was used without further purification. All the preparation processes were carried out under ambient conditions. The two-dimensional (2D) self-assembly of the PCDYol was obtained by quasi-Langmuir-Blodgett (quasi-LB) method [9,10] or by spin-coating. Sample preparation by quasi-LB method was carried out as follows. The PCDYol solution in chloroform $80 \mu \mathrm{L}$ at $0.1 \mathrm{mg} / \mathrm{mL}$ was placed onto a purified water surface in a Petri dish with an inner diameter of about $34 \mathrm{~mm}$. The temperature of the water was maintained at $20^{\circ} \mathrm{C}$. After the chloroform was evaporated, a part of the thin film was detached from water interface by bringing the horizontally oriented HOPG (Advanced Ceramics Co., Tucson, AZ, USA grade ZYH) in contact with the film from the air side. The molecules were transferred from the water surface to the freshly cleaved (0001) surface of the HOPG substrate. For the preparation by spin-coating, the PCDYol solution in chloroform at the concentration of the $0.07 \mathrm{mg} / \mathrm{mL}$ was used. The several $\mu \mathrm{L}$ drops of the PCDYol solution were placed directly onto the surface of the HOPG at the rotational speed of $2.0 \times 10^{3} \mathrm{rpm}$. Sample heating was conducted in air, using a conventional hot plate. The heating temperatures were in the range of 30 to $120^{\circ} \mathrm{C}$. The sample was picked up from the hot plate using tweezers and put on a laboratory table at room temperature. The temperature of the sample surface dropped to room temperature within one minute.

\subsection{Scanning Probe Microscopy}

The scanning probe microscope (SPM) images were acquired with a Nanoscope IIIa SPM (Digital Instruments, Santa Barbara, CA, USA) at room temperature in air. The mechanically cut Pt/Ir wires (90/10) were used as STM probes. The sample bias voltage (tip grounded) -800 to $800 \mathrm{mV}$ and tunneling current 6 to $20 \mathrm{pA}$ were applied in constant current mode. For the AFM observation, commercial silicon cantilevers (OMCL-AC200TS-R3, Olympus Corporation, Nagano, Japan) with spring constants of 2.8 to $21 \mathrm{Nm}^{-1}$ and resonance frequencies of 100 to $200 \mathrm{kHz}$ were used in tapping mode.

\section{Results and Discussion}

Normally, PCDYol monomolecular films prepared by quasi-LB method are 2D polycrystals composed of small domains of $\mathrm{H}$ and $\mathrm{P}$ arrangements with an average size of $80 \mathrm{~nm}$. Figure 2 shows typical STM images of PCDYol monomolecular films obtained by quasi-LB method. In the film, the domains of $\mathrm{H}$ and $\mathrm{P}$ arrangements coexist. Both domains exhibit lamellar structures, where the periods coincide with the PCDYol dimers. In H arrangement, the extended PCDYol chains exhibit a feather-like pattern, as shown in Figure 2a, and the lamellar interval determined by STM observation is $6.2 \pm 0.2 \mathrm{~nm}$. On the other hand, in P arrangement, the PCDYol molecules align in the same direction as shown in Figure $2 \mathrm{~b}$. The period of the lamellar structure in $\mathrm{P}$ arrangement is estimated to be $6.8 \pm 0.2 \mathrm{~nm}$, which is larger than that in H arrangement. For STM and AFM images of PCDYol monomolecular films, we can easily identify $\mathrm{H}$ and $\mathrm{P}$ arrangement domains by the difference of the period. 


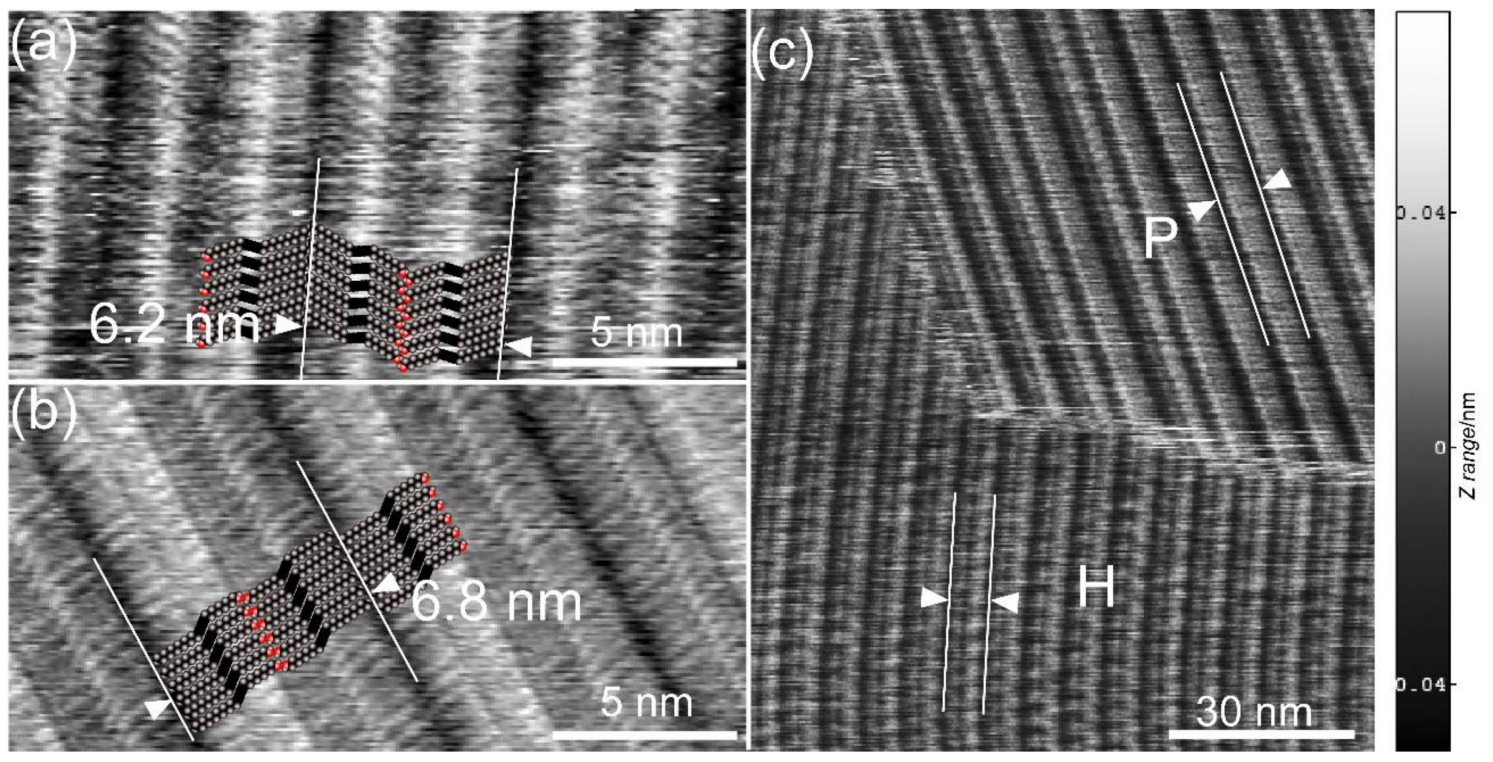

Figure 2. STM height images of a PCDYol monomolecular film formed on a HOPG surface by quasi-LB method. The dimer lengths are suggested by pairs of white lines. High-resolution images of (a) $\mathrm{H}$ arrangement $\left(I_{\text {set }}=20 \mathrm{pA}, V_{\text {bias }}=-800 \mathrm{mV}, 7.5 \mathrm{~Hz}\right)$ and $(\mathbf{b}) \mathrm{P}$ arrangement $\left(I_{\text {set }}=10 \mathrm{pA}, V_{\text {bias }}=800 \mathrm{mV}\right.$, $8.1 \mathrm{~Hz}$ ). The adsorption model is superimposed at the bottom. (c) A large-area image showing the coexistence of $\mathrm{H}$ and $\mathrm{P}$ domains $\left(I_{\text {set }}=10 \mathrm{pA}, V_{\text {bias }}=-100 \mathrm{mV}, 3.9 \mathrm{~Hz}\right)$. The $\mathrm{Z}$ range is presented on the right side.

At room temperature, the structures of PCDYol monomolecular films are frozen. After keeping the samples at room temperature for two weeks, no distinguishable changes in the film structures were observed. To investigate thermodynamic stability of the polymorphs, we annealed the PCDYol monomolecular films above room temperature. We found that above $40{ }^{\circ} \mathrm{C}$, relaxation of the film structure is effectively induced. Figure 3 shows the structural changes of the PCDYol monomolecular film observed after annealing at $50{ }^{\circ} \mathrm{C}$. On the as-grown monomolecular film shown in Figure $3 \mathrm{a}$, the area fraction of the $\mathrm{P}$ arrangement region is $40 \%$. Figure $3 \mathrm{~b}, \mathrm{c}$ shows the structures after annealing for 300 and $3600 \mathrm{~s}$, respectively. In addition to the grain growth by Ostwald ripening, P arrangement domains are observed to be predominant after annealing. On the monomolecular film annealed for $300 \mathrm{~s}$, the area ratio of $\mathrm{P}$ arrangement region increases up to $80 \%$. After $3600 \mathrm{~s}$ annealing, the domains of $\mathrm{P}$ arrangement cover almost the entire surface, as shown in Figure $3 \mathrm{c}$. These results demonstrate that $\mathrm{P}$ arrangement is thermodynamically stable, while $\mathrm{H}$ arrangement is metastable. 

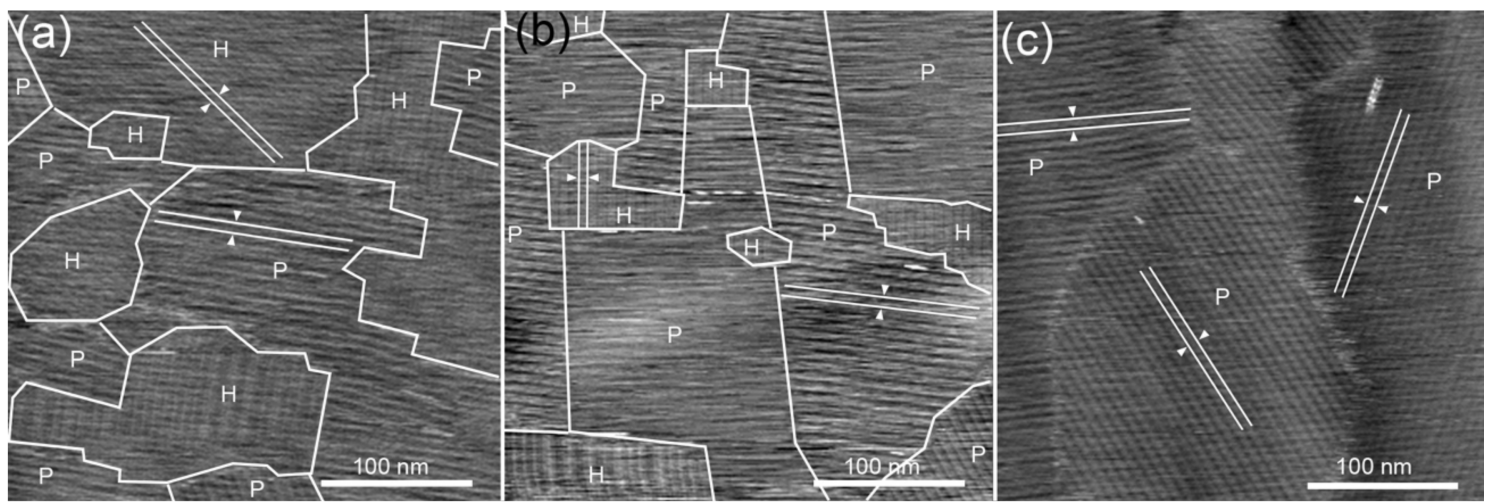

Figure 3. Morphological changes observed after annealing at $50{ }^{\circ} \mathrm{C}$. (a) Typical STM image showing coexistence of $\mathrm{H}$ and $\mathrm{P}$ arrangements in the PCDYol film prepared by quasi-LB $\left(I_{\mathrm{set}}=6 \mathrm{pA}\right.$, $V_{\text {bias }}=800 \mathrm{mV}, 3.6 \mathrm{~Hz}$ ). Domain boundaries are indicated by white lines. The area ratio of $\mathrm{P}$ arrangement is 0.4 . The stripe intervals of $\mathrm{H}$ and $\mathrm{P}$ arrangements are suggested by pairs of white lines. $(\mathbf{b}, \mathbf{c})$ STM images of the film after annealing at $50{ }^{\circ} \mathrm{C}$ for $(\mathbf{b}) 300 \mathrm{~s}\left(I_{\text {set }}=6 \mathrm{pA}, V_{\text {bias }}=800 \mathrm{mV}, 3.6 \mathrm{~Hz}\right)$ and $\left(\right.$ c) $3600 \mathrm{~s}\left(I_{\text {set }}=10 \mathrm{pA}, V_{\text {bias }}=-500 \mathrm{mV}, 3.6 \mathrm{~Hz}\right)$.

Similar behavior is observed in structural changes of monomolecular films induced by STM scanning. We found that continuous STM scanning at room temperature causes morphological changes of the PCDYol monomolecular films. The detailed mechanism of the STM-induced morphological changes is not clear at present, although the reordering effect of the STM tip due to electrostatic interaction has been reported for monolayers of a DA compound 10,12-pentacosadiynoic acid [11]. Figure 4 shows snapshots during continuous STM scanning of the same region of $300 \mathrm{~nm} \times 300 \mathrm{~nm}$. In the first STM image shown in Figure 4a, P and $\mathrm{H}$ arrangement domains coexist. In the 8th scan, shown in Figure $4 \mathrm{~b}$, the $\mathrm{H}$ arrangement domain indicated in Figure 4a has shrunk from $8.3 \times 10^{3} \mathrm{~nm}^{2}$ down to $5.0 \times 10^{3} \mathrm{~nm}^{2}$. In the 16th scan, the $\mathrm{H}$ arrangement domain has completely disappeared, as shown in Figure 4c. In the two consecutive images shown in Figure 5, we can see the process by which the $\mathrm{P}$ arrangement domain invades the neighboring $\mathrm{H}$ arrangement domain. The single column of $\mathrm{H}$ arrangement surrounded by white line in Figure 5a transforms to $\mathrm{P}$ arrangement by growth of the three columns in the P domain toward the upper right. The STM-induced transformation from $\mathrm{H}$ to $\mathrm{P}$ arrangement strongly supports the conclusion that $\mathrm{P}$ arrangement is thermodynamically stable.
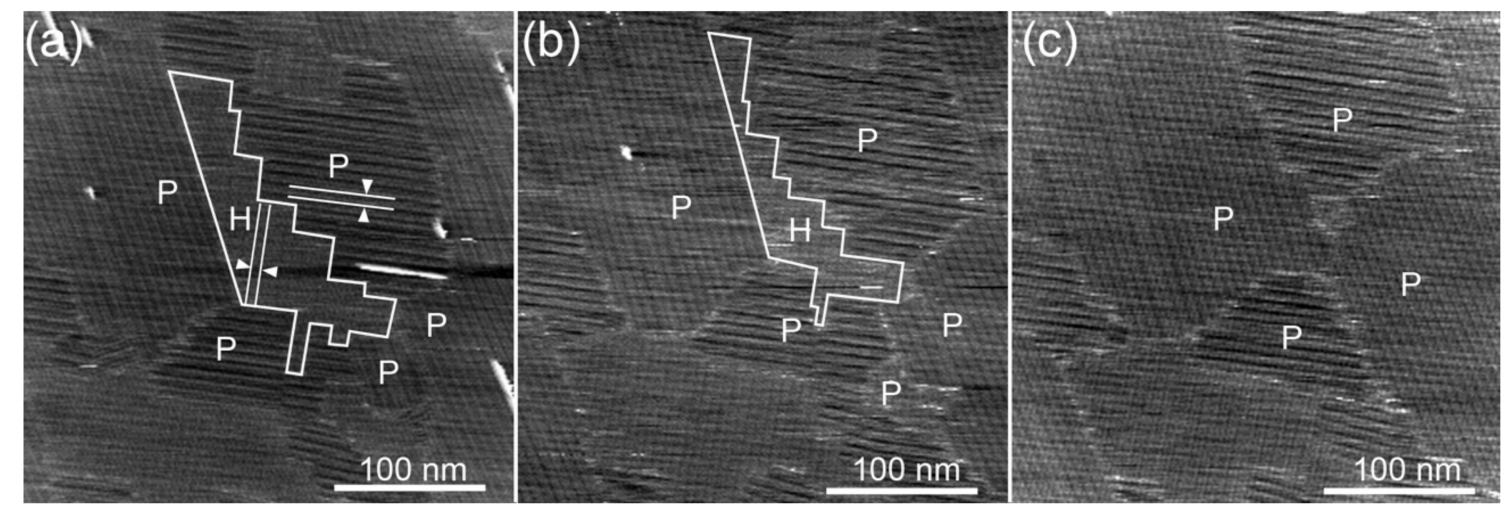

Figure 4. Morphological evolution of a PCDYol film by continuous STM scanning at room temperature $\left(I_{\text {set }}=10 \mathrm{pA}, V_{\text {bias }}=-800 \mathrm{mV}, 3.6 \mathrm{~Hz}\right)$. These images were obtained at the same surface region from the (a) first, (b) 8th, and (c) 16th STM scans. The lamellar structure of $\mathrm{H}$ arrangement can be seen, and is indicated by a pair of white lines. The $\mathrm{H}$ domain indicated by white line in (a) shrinks and eventually disappears during the continuous STM scanning. 


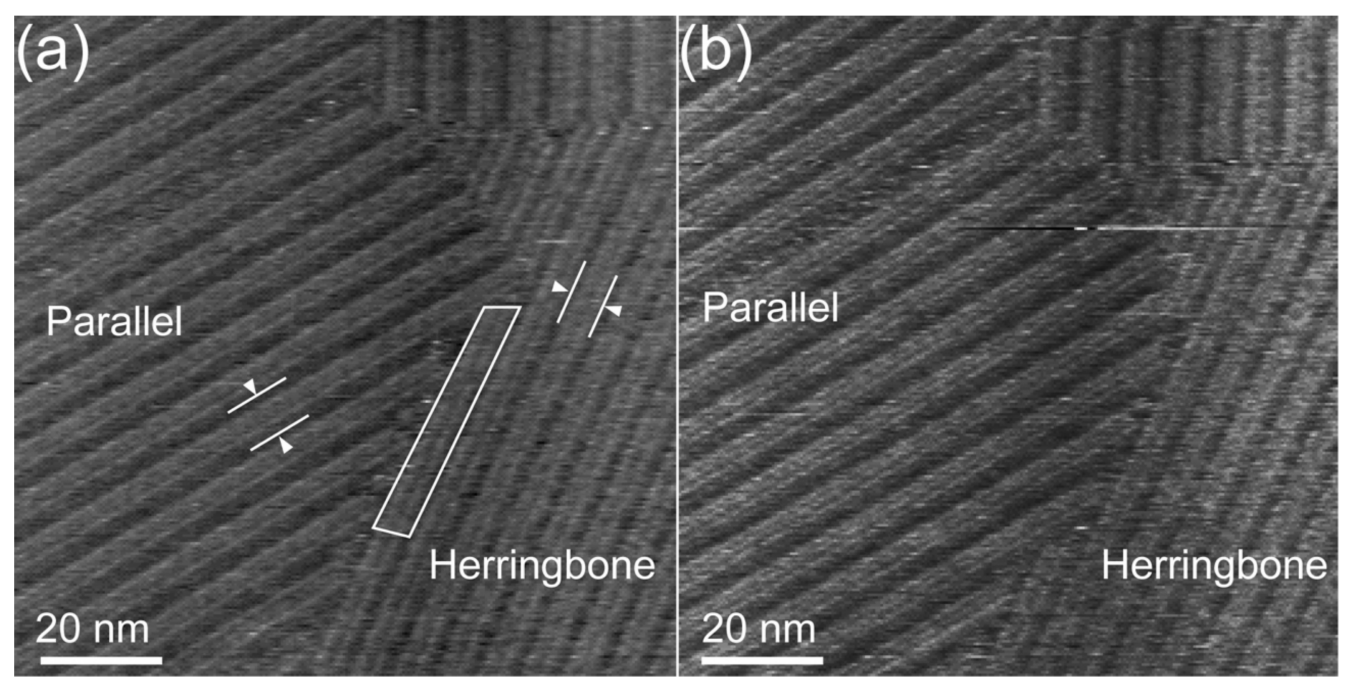

Figure 5. Successive STM images showing detailed features of the movement of the $\mathrm{P} / \mathrm{H}$ interface by STM scanning $\left(I_{\text {set }}=10 \mathrm{pA}, V_{\text {bias }}=-800 \mathrm{mV}, 3.5 \mathrm{~Hz}\right)$. (a) The boundary between $\mathrm{P}$ and $\mathrm{H}$ domains is seen at the center of the image. (b) The part of the $\mathrm{H}$ domain surrounded by the white line in (a) becomes incorporated into the $\mathrm{P}$ domain on the left side.

Finally, we show that drastic morphological changes of PCDYol monomolecular films occur when the annealing temperature is increased up to $80{ }^{\circ} \mathrm{C}$. Figure 6a shows the AFM image of the PCDYol monomolecular film formed by spin-coating. Before annealing, the surface was completely covered by only $\mathrm{H}$ arrangement domains. After annealing the sample in the range of 40 to $70{ }^{\circ} \mathrm{C}$, the P domains are observed as shown in Figure 6b. However, Figure $6 \mathrm{c}$ shows that the stripe contrasts disappear in the wide range after $80^{\circ} \mathrm{C}$ annealing for $600 \mathrm{~s}$. There are many islands, which are imaged $0.2 \mathrm{~nm}$ higher than the surroundings as shown in the inset of the figure. As clearly found in the enlarged image (Figure 6d), the lamellar structure of P arrangement is observed only on the islands, and the extensive region around the islands shows no regular pattern as reported on the liquids of other compounds [12-14]. Considering the molecular weight, it is difficult to expect that PCDYol molecules evaporate from the surface in an amount detectable by AFM after annealing at $80^{\circ} \mathrm{C}$ for $600 \mathrm{~s}$. Moreover, the height difference between the island and the surroundings is much smaller than the thickness of PCDYol molecule. Therefore, we consider that in the region other than the islands PCDYol molecules remain in glass state. The height difference between the island and surrounding in the AFM image is probably artificial, caused by the deformation of the soft glass region due to the mechanical force during the AFM scanning. In the quenched disordered phase, as already reported for the thin film of $\mathrm{C}_{32} \mathrm{H}_{66}$ [15], the chain molecules probably have conformational defects. It is therefore reasonable to speculate that the affinity to the HOPG surface decreases in the glass region, allowing the PCDYol to move away from the AFM tip. At $80^{\circ} \mathrm{C}$ ordered monomolecular films on HOPG melt into liquid. We infer that the islands of $\mathrm{P}$ arrangement nucleated during quenching down to room temperature or formed during the rising of temperature. This melting point of $80^{\circ} \mathrm{C}$ for the ordered monomolecular film on HOPG is about $20^{\circ} \mathrm{C}$ higher than that of the bulk crystal of $59^{\circ} \mathrm{C}$. Similarly, it has been reported that the melting points of the monomolecular films of $n$-alcohols on the graphite surface are higher than those of the bulk solids [16,17]. 

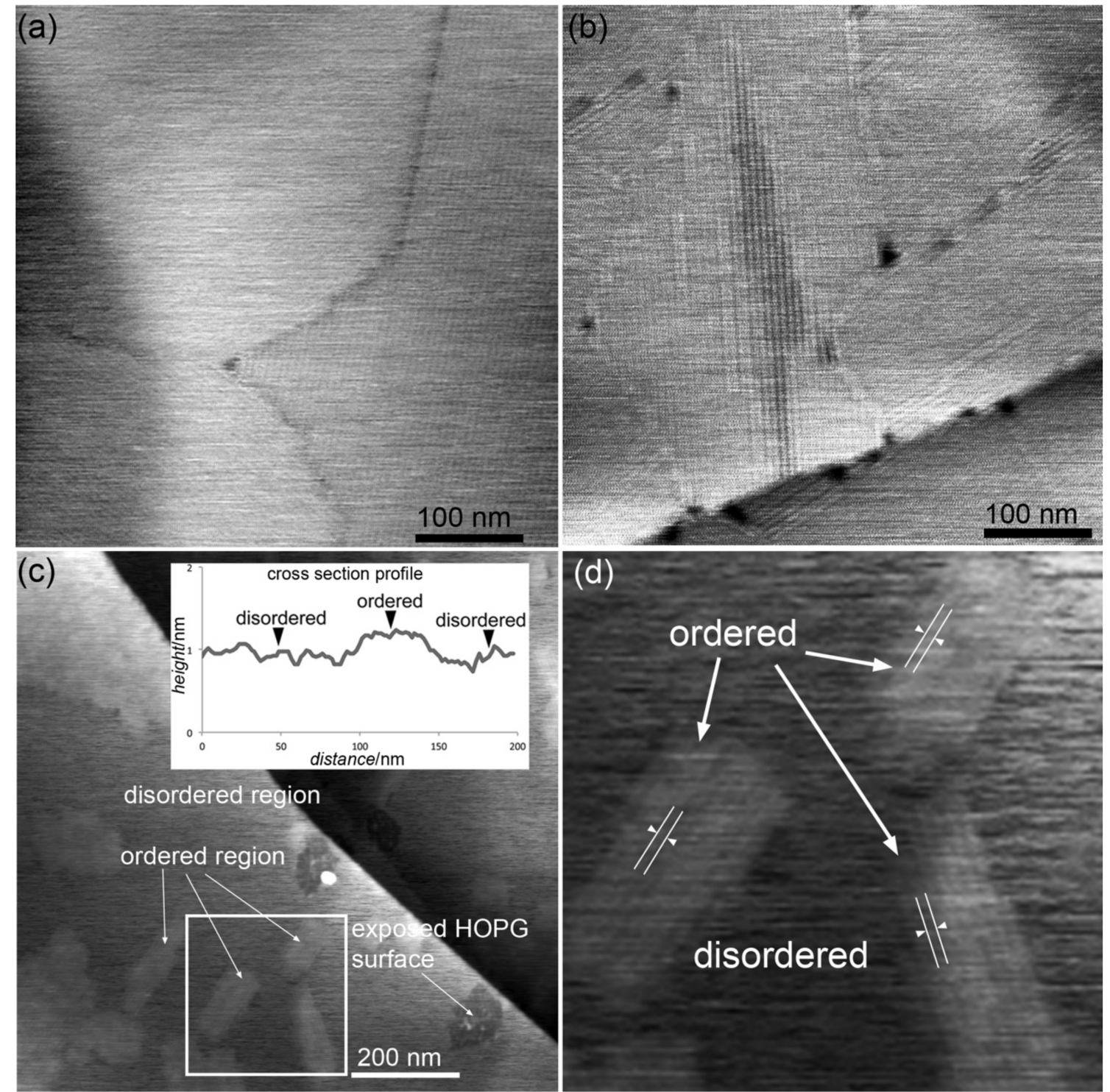

Figure 6. (a) AFM image of a PCDYol monomolecular film prepared by spin-coating. Three $\mathrm{H}$ arrangement domains cover the entire scan area. (b) AFM image of the P domains observed after annealing at $70{ }^{\circ} \mathrm{C}$ for $600 \mathrm{~s}$. (c) AFM image of the film obtained after annealing at $80{ }^{\circ} \mathrm{C}$ for $600 \mathrm{~s}$. In the inset, a cross section profile along the line scan in the horizontal direction is shown. (d) The enlarged image of the square region indicated in (c). On the island surface, the lamellar structure of P arrangement is observed. No regular pattern is seen over the surrounding sea in glass state.

\section{Conclusions}

We studied the thermodynamic stability for the two polymorphic forms of the PCDYol monomolecular films on HOPG. We observed that polymorphic changes from $\mathrm{H}$ to $\mathrm{P}$ arrangement occur by annealing at above $40{ }^{\circ} \mathrm{C}$ and by the stimulation due to continuous STM scanning. These observations clearly demonstrate that $\mathrm{P}$ arrangement is thermodynamically stable, while $\mathrm{H}$ arrangement is metastable. Furthermore, we estimate that the melting point of the $\mathrm{P}$ arrangement film is about $80^{\circ} \mathrm{C}$, which is $20^{\circ} \mathrm{C}$ higher than that of its bulk crystal. 
Acknowledgments: This work is Contribution No. 58 from the Research Center for Structural Thermodynamics.

Author Contributions: D.T. conceived and designed the experiments; D.T. performed the experiments; D.T. and K.S. analyzed the data; D.T. and K.S. wrote the paper.

Conflicts of Interest: The authors declare no conflict of interest.

\section{References}

1. Lafferentz, L.; Eberhardt, V.; Dri, C.; Africh, C.; Comelli, G.; Esch, F.; Hecht, S.; Grill, L. Controlling On-Surface Polymerization by Hierarchical and Substrate-Directed Growth. Nat. Chem. 2012, 4, 215-220. [CrossRef] [PubMed]

2. Cai, J.; Ruffieux, P.; Jaafar, R.; Bieri, M.; Braun, T.; Blankenburg, S.; Muoth, M.; Seitsonen, A.P.; Saleh, M.; Feng, X.; et al. Atomically Precise Bottom-up Fabrication of Graphene Nanoribbons. Nature 2010, 466, 470-473. [CrossRef] [PubMed]

3. Liu, X.; Guan, C.; Ding, S.; Wang, W.; Yan, H.; Wang, D.; Wan, L. On-Surface Synthesis of Single-Layered Two-Dimensional Covalent Organic Frameworks via Solid-Vapor Interface Reactions. J. Am. Chem. Soc. 2013, 135, 10470-10474. [CrossRef] [PubMed]

4. Han, P.; Akagi, K.; Canova, F.F.; Mutoh, H.; Shiraki, S.; Iwaya, K.; Weiss, P.S.; Asao, N.; Hitosugi, T. Bottom-Up Graphene-Nanoribbon Fabrication Reveals Chiral Edges and Enantioselectivity. ACS Nano 2014, 8, 9181-9187. [CrossRef] [PubMed]

5. Zhang, H.; Gong, Z.; Sun, K.; Duan, R.; Ji, P.; Li, L.; Li, C.; Müllen, K.; Chi, L. Two-Dimensional Chirality Transfer via On-Surface Reaction. J. Am. Chem. Soc. 2016, 138, 11743-11748. [CrossRef] [PubMed]

6. Okawa, Y.; Aono, M. Nanoscale control of chain polymerization. Nature 2001, 409, 683-684. [CrossRef] [PubMed]

7. Okawa, Y.; Mandal, S.K.; Hu, C.; Tateyama, Y.; Goedecker, S.; Tsukamoto, S.; Hasegawa, T.; Gimzewski, J.K.; Aono, M. Chemical Wiring and Soldering toward All-Molecule Electronic Circuitry. J. Am. Chem. Soc. 2011, 133, 8227-8233. [CrossRef] [PubMed]

8. Nakaya, M.; Okawa, Y.; Joachim, C.; Aono, M.; Nakayama, T. Nanojunction between Fullerene and One-Dimensional Conductive Polymer on Solid Surfaces. ACS Nano 2014, 8, 12259-12264. [CrossRef] [PubMed]

9. Takajo, D.; Inaba, A.; Sudoh, K. Two Polymorphic Forms of 10,12-Pentacosadiyn-1-ol Molecular Layers on Graphite Transferred from an Aqueous Surface. Surf. Sci. 2014, 620, 38-44. [CrossRef]

10. Takajo, D.; Inaba, A.; Sudoh, K. Two-Dimensional Solid-State Topochemical Reactions of 10,12-Pentacosadiyn-1-ol Adsorbed on Graphite. Langmuir 2014, 30, 2738-2744. [CrossRef] [PubMed]

11. Giridharagopal, R.; Kelly, K.F. STM-Induced Desorption of Polydiacetylene Nanowires and Reordering via Molecular Cascades. J. Phys. Chem. C 2007, 111, 6161-6166. [CrossRef]

12. Feenstra, R.M.; Slavin, A.J.; Held, G.A.; Lutz, M.A. Edge Melting of the Ge(111) Surface Studied by Scanning Tunneling Microscopy. Ultramicroscopy 1992, 42, 33-40. [CrossRef]

13. Poirier, G.E.; Tarlov, M.J.; Rushmeier, H.E. Two-Dimensional Liquid Phase and the $p \times \sqrt{ } 3$ Phase of Alkanethiol Self-Assembled Monolayers on Au(111). Langmuir 1994, 10, 3383-3386. [CrossRef]

14. Kondoh, H.; Kodama, C.; Sumida, H.; Nozoye, H. Molecular Processes of Adsorption and Desorption of Alkanethiol Monolayers on Au(111). J. Chem. Phys. 1999, 111, 1175-1184. [CrossRef]

15. Bucher, J.; Roeder, H.; Kern, K. Thermally Induced Disorder and Conformational Defects of Alkane Monolayers on Graphite. Surf. Sci. 1993, 289, 370-380. [CrossRef]

16. Morishige, K.; Kato, T. Chain-Length Dependence of Melting of $n$-Alcohol Monolayers Adsorbed on Graphite: $n$-Hexanol, n-Heptanol, n-Octanol, and n-Nonanol. J. Chem. Phys. 1999, 111, 7095-7102. [CrossRef]

17. Morishige, K. Structure and Melting of a Monolayer Ethanol Film on Graphite. J. Chem. Phys. 1992, 97, 2084-2089. [CrossRef] 